\title{
Erratum
}

Tijdschr Jeugdgezondheidsz (2021) 53:96

https://doi.org/10.1007/s12452-021-00253-8

Q

Check for
updates

\section{Erratum to: Gemiste lessen, gemiste kansen}

\section{Y. Vanneste $\cdot$ K. Hoppenbrouwers $\cdot$ M. Boere-Boonekamp}

(C) Bohn Stafleu van Loghum is een imprint van Springer Media B.V., onderdeel van Springer Nature 2021

\section{Erratum to:}

Tijdschr Jeugdgezondheidsz 2021

https://doi.org/10.1007/s12452-021-00250-x

De affiliaties van twee auteurs van het redactioneel van nummer $2 / 3$ zijn omgewisseld. De juiste affiliaties zijn:

- K. Hoppenbrouwers: Centrum Omgeving en Gezondheid, Jeugdgezondheidszorg, Universiteit Leuven, Leuven, België

- M. Boere-Boonekamp: Universiteit Twente, Enschede, Nederland

Het oorspronkelijke artikel is gecorrigeerd.

De online versie van de originele bijdrage vindt $\mathrm{u}$ onder https://doi.org/10.1007/s12452-021-00250-x.

Y. Vanneste $(\triangle)$

Nederlands Centrum Jeugdgezondheid, Utrecht, Nederland yvanneste@ncj.nl

K. Hoppenbrouwers

Centrum Omgeving en Gezondheid, Jeugdgezondheidszorg,

Universiteit Leuven, Leuven, België

M. Boere-Boonekamp

Universiteit Twente, Enschede, Nederland 